\title{
The Antibiotic Properties of Fifty-two Strains of Fusarium
}

\author{
By MARGARET S. LACEY \\ Imperial College of Science and Technology, London
}

SUMMARY: Culture fluids of fifty-two strains of Fusarium spp. were examined for antibacterial activity. Four groups were distinguished: $(a)$ six strains equally active against a strain of Staphylococcus aureus and Mycobacterium phlei strain $1 ;(b)$ sixteen strains much less active against Staph. aureus than against Myco. phlei $1 ;(c)$ fourteen strains inactive against Staph. aureus, active against Myco. phlei $1 ;(d)$ sixteen strains inactive against both Staph. aureus and Myco. phlei 1 , of which six were active against Myco. phlei strain 2.

Examination of pure antibiotic substances isolated from the culture fluids of nine of the strains showed them to be both bacteriostatic and bactericidal; they were very active against mycobacteria and effective to a lesser degree against other Grampositive bacteria. They were ineffective against Gram-negative bacteria and fungi.

Earlier papers described the production of an antibiotic pigment, javanicin, from Fusarium javanicum (Arnstein, Cook \& Lacey, 1946a,b), and the isolation of five antibiotic substances from strains of $F$. lateritium, $F$. fructigenum, $F$. sambucinum and $\boldsymbol{F}$. avenaceum respectively (Cook, Cox, Farmer \& Lacey, 1947). The last paper also recorded the preliminary sorting of twenty-two Fusarium strains into four groups according to the type of antibiotic activity of the culture fluids. Thirty more strains have now been examined, making fifty-two in all, and in some cases attempts have been made to isolate the active principles.

\section{EXPERIMENTAL}

\section{Methods of testing for antibiotic activity}

For general routine examinations the Fusarium cultures were grown at $25^{\circ}$ in $150 \mathrm{ml}$. conical flasks containing $50 \mathrm{ml}$. of a medium consisting of Bactotryptone or Eupeptone, 10 g.; sodium chloride, 5 g.; glucose, 40 g.; in 1 l. of water. This medium was the most satisfactory for the preliminary examination, because Fusarium strains capable of antibacterial activity always produced active material in this medium, though not always of the highest possible potency. At frequent intervals from the 3rd to the 28th day samples were withdrawn by sterile pipettes from each flask and tested for antibacterial activity.

Two bacterial strains, Staphylococcus aureus and Mycobacterium phlei strain 1, were used as routine test organisms. In many cases Myco. phlei strain 2, Streptococcus pyogenes, Bacillus subtilis and Corynebacterium fascians, representing different types of Gram-positive bacteria, and the Gram-negative species Escherichia coli, Pseudomonas fluorescens and Ps. aeruginosa were also used. Activity against the Gram-positive species varied with different Fusarium strains, but all the strains were inactive against the Gram-negative bacteria. 
The Fusarium strains were usually much more effective against Myco. phlei than against Staph. aureus, Strep. pyogenes or B. subtilis. The two strains of Myco. phlei varied considerably in their susceptibility to the various Fusarium strains; Myco. phlei 2, which in tests against pure antibiotic substances resembled Myco. tuberculosis more closely than did Myco. phlei 1, was sometimes more and sometimes less susceptible than Myco. phlei 1. The Fusarium culture fluids were strongly active against $C$. fascians (a plant parasite of diphtheroid type).

Two methods of testing for antibacterial activity were used: (a) the agarplate method, in which the culture fluids were filled into holes cut with a corkborer in nutrient agar plates seeded with the test bacterium; $(b)$ by serial dilution in broth. Plates and tubes were incubated at $37^{\circ}\left(30^{\circ}\right.$ for $C$. fascians), and the results read the next day when Staph. aureus, Strep. pyogenes or $B$. subtilis was the test organism, and after 2 or 3 days with Myco. phlei and $C$. fascians. Most of the tests were made by the broth-dilution method but the agar-plate method was useful for determining the first appearance of antibiotic activity.

\section{Measurement of potency}

Antibiotic potency is expressed as the highest dilution of fluid tested which completely inhibited the growth of the test bacteria; thus a potency of $1 / 200$ means that $1 / 200$ was the maximum inhibiting dilution of a given culture fluid.

\section{Development of antibiotic activity}

In general, culture fluids were feebly active on the fourth day and reached their maximum potency at 10-14 days. With some strains (e.g. F. lateritium, $F$. sambucinum) the maximum potency was maintained with little change for a month or more. For others, notably in members of group $\mathrm{C}$ (see below), the maximum potency was maintained for $24-48 \mathrm{hr}$. only, followed by a rapid fall to zero.

Except with $F$. javanicum cultures, where potencies of $1 / 100$ to $1 / 200$ were obtained, the potency of the crude culture fluids was low, 1/20 to 1/25 against Myco. phlei usually being the maximum. Those antibiotics (lateritiin, etc.) which were isolated were very sparingly water-soluble; this may account for the small quantity present in the culture fluids.

All the Fusarium cultures produced acid at first, followed later by alkali. Thus an initial $\mathrm{pH}$ value of 6.5 would fall to $\mathrm{pH} 4-5$ during the first few days, after which there would be a gradual rise to $\mathrm{pH}$ 8-8.5. There was no correlation between $\mathrm{pH}$ value and antibiotic production.

The fifty-two Fusarium strains were sorted into four main groups according to the activity of the crude culture fluids against Staph. aureus and Myco. phlei 1:

Group A: Six strains equally active against Myco. phlei 1 and Staph. aureus.

Group B: Sixteen strains considerably more active against Myco. phlei 1 than against Staph. aureus. 
Group C: Fourteen strains active against Myco. phlei 1, inactive against Staph. aureus.

Group D: Sixteen strains inactive against both Myco. phlei 1 and Staph. aureus.

Table 1 summarizes the results of testing the crude culture fluids of the fifty-two Fusarium strains. In no case was the test positive against Staph. aureus and negative against $M y c o$. phlei nor was there ever greater activity against Staph. aureus than against Myco. phlei 1.

Table 1. Activity of fifty-two Fusarium strains against Mycobacterium phlei 1 and Staphylococcus aureus

\begin{tabular}{|c|c|c|}
\hline \multirow[b]{2}{*}{ Fusarium strains } & \multirow{2}{*}{ Myco.phlei 1} & \multirow{2}{*}{ Staph. aureus } \\
\hline & & \\
\hline \multicolumn{3}{|l|}{ Group A } \\
\hline F. javanicum & $\mathbf{1} / \mathbf{2 0 0}$ & $1 / 200$ \\
\hline F. dianthi 1 and 2 & $1 / 40$ & $1 / 40$ \\
\hline F. 6 & $1 / 10$ & $1 / 10$ \\
\hline F. 157 & $1 / 40$ & $1 / 40$ \\
\hline F. 64 & $1 / 50$ & $1 / 50$ \\
\hline \multicolumn{3}{|l|}{ Group B } \\
\hline F. lateritium, four strains & $1 / 20$ & $\mathbf{1} / \mathbf{5}$ \\
\hline F. sambucinum 1 & $1 / 25$ & $1 / 5$ \\
\hline F. avenaceum & $1 / 20$ & $<1 / 5$ \\
\hline F. fructigenum, F. 135, F. 136, F. 137, F. 138 & $1 / 20$ & $\begin{array}{l}\text { Trace or none, } \\
\text { very transitory }\end{array}$ \\
\hline $\begin{array}{l}F . \text { dianthi } 3, F . \text { lini, } F . \text { culmorum } 1, F . \text { monili- } \\
\text { forme-subglutinans } 1, F .63\end{array}$ & $\mathbf{1} / \mathbf{5}$ & Trace \\
\hline \multicolumn{3}{|l|}{ Group C } \\
\hline F. $01, F \cdot 128, F \cdot 181$ & $1 / 40$ & $\mathbf{0}$ \\
\hline F. $72, F .117, F .126, F .130, F .133$ & $1 / 20$ & $\mathbf{0}$ \\
\hline F. culmorum 2, F. poae, F. 101, F. 125 & $\mathbf{1} / \mathbf{1 0}$ & $\mathbf{0}$ \\
\hline F. sambucinum 2, F. 129 & $1 / 5$ & $\mathbf{0}$ \\
\hline \multicolumn{3}{|l|}{ Group D } \\
\hline $\begin{array}{l}\text { F. aquaeductum, F. culmorum } 3 \\
\text { F. oxysporum cubense } \\
\text { F. moniliforme-subglutinans } 2\end{array}$ & & \\
\hline $\begin{array}{l}F . \text { dimerium, } F . \text { caeruleum } \\
F . \text { sambucinum } 3, F .10, F .88, F .94, \\
F \text { 95, F. 96, F. } 97, F .124, F .127, F .182\end{array}$ & $\mathbf{0}$ & $\mathbf{0}$ \\
\hline
\end{tabular}

Group $A$. Although the six strains were alike in producing equal activity against Myco. phlei 1 and Staph. aureus, the antibiotic substances produced by the different strains appeared to differ. $F$. javanicum is the only member of this group from which a pure antibiotic substance was isolated, but enough progress was made in the extraction of the active principles from the other strains to demonstrate their chemical, as well as their biological, diversity. $F$. javanicum differed from the other fifty-one strains in producing a soluble blood-red antibacterial pigment, javanicin (Arnstein et al. 1946a,b). Many of the other strains developed red, orange or yellow pigmentation of the mycelial 
felt and sometimes a yellow pigment diffused into the medium, but this was inactive and there was no correlation between pigment production and antibiotic activity.

$F$. dianthi, strains 1 and 2, and F. 157 (?F.pisi, isolated from a foot-rot of peas) were similar in antibiotic activity. They were equally active against Staph. aureus and the two strains of Myco. phlei, and less active against Strep. pyogenes and $B$. subtilis. After the maximum potency was reached on the 7th to the 11th day there was a somewhat rapid fall to $1 / 5$, which was still shown by month-old cultures. T. H. Farmer, who attempted the extraction of the antibiotics from these cultures, was unable to isolate a pure substance, but his results suggested the presence of two active principles, one of which might be a peptide.

Strain $F$. 64, from potato-rot, is of interest on account of the erratic and peculiar character of the antibiotic production. Repeated tests, both of the parent culture and of single spore isolations from the parent, exhibited the same phenomena. When $F$. 64 was grown on the standard Eupeptone medium, a potency of $1 / 10$ on the 4th day was followed by a fall to zero on the 6th or 7th day. A second rise in activity and occasionally a second less marked fall then occurred, the maximum potency (occasionally up to $1 / 50$ ) being reached about the 11th day. A slow decline followed, usually with slight further rises and falls, until by about the 21st day the culture fluids were inactive. In Czapek-Dox medium there was no activity until the 9th day; a maximum potency of 1/10 was reached by the 11th day followed by an irregular rise and fall in strength from day to day similar to the results with the Eupeptone medium. The addition of $\mathbf{0 . 2} \%$ Yeastrel to the Czapek-Dox medium almost suppressed antibiotic production. Yet another type of activity developed in a $0.5 \%$ Marmite $1 \%$ glucose medium. No activity against Staph. aureus was developed, but a potency of $1 / 25$ against $M y c o$. phlei was reached on the 10th day: no day to day irregularities occurred in this medium.

A second peculiar phenomenon was repeatedly observed in agar-plate tests of F. 64 culture fluids against Staph. aureus. Instead of the usual clear and sharply defined zone of inhibition surrounding the cup there were frequently two zones of inhibition, an inner zone and an outer one, somewhat narrower, separated by a ring of very heavy staphylococcal growth: sometimes there was only partial inhibition of growth in the outer zone. This suggests interference with the inhibition mechanism at a certain critical concentration of the antibiotic.

Group $B$. The sixteen strains in this group were very similar in antibiotic activity against Myco. phlei 1 . The activity appeared on the 5th or 6th day, reached a maximum at 12-14 days and was maintained at this potency for at least 1 month. The strains were tested on a variety of media to find the optimum conditions for antibiotic production. A medium containing Bactotryptone always gave the best results, but as the supply of this material was insufficient for the large-scale cultivation necessary for chemical work, substitutes were tested; of these Eupeptone was found to be the most satisfactory. The strains varied in their optimum glucose requirements and $\boldsymbol{F}$. sambucinum was alone in producing a potency of $1 / 20$ in a Bactotryptone medium without glucose. 
Culture fluids active against Myco. phlei 1 at $1 / 20$ dilution were usually effective against Staph. aureus at $1 / 5$, but $F$. fructigenum and four strains isolated from cob-nuts $(F .135, F, 136, F .137$ and $F .138)$ were very feebly active against $S$ taph. aureus from the 4 th to the 7 th day only, and by the time the maximum potency (1/20) against $M y c o$. phlei was reached the culture fluids were completely inactive against $S t a p h$. aureus. Later it was found that impure preparations of the antibiotics from the culture fluids of these five strains were also inactive against Staph. aureus, although they increased in potency against Myco. phlei as purification proceeded. However, when the pure antibiotics were finally obtained, they were as potent against Staph. aureus as sambucinin and more potent than avenacein.

A second unexplained phenomenon was the erratic inhibition of Myco. phlei 1 in dilution tests of crude extracts of $\boldsymbol{F}$. fructigenum. For example, in one test there was thick growth of Myco. phlei in the 1/50 dilution but complete inhibition in the $1 / 100$ and $1 / 200$ dilutions. This phenomenon occurred too frequently to be attributable to errors in testing. It occurred only with the impure preparation of the antibiotic; the pure substance behaved consistently. In these cases, as in $F$. 64 of group A, some substance appears to be present in the culture fluids which persists as an impurity in the extracts and which interferes with the inhibiting mechanism at certain concentrations of the antibiotic. Pure crystalline antibiotic substances were isolated from eight strains in this group (see below).

Group $C$. The antibiotic activity and chemical behaviour of these fourteen strains were so markedly different from those of group $B$ as to justify their assignment to a separate group. The culture fluids in any medium and after any period of growth were completely inactive against Staph. aureus and the active principles were markedly unstable. Maximum potency, and the time taken to reach it, varied with different strains, but in every case there was a rapid rise and fall in activity against Myco. phlei 1, the maximum potency often being maintained for 24-48 hr. only; after 14-21 days the fluids were almost or entirely inactive. Attempts to isolate the active principles by my colleagues T. H. Farmer and S. F. Cox showed that the antibacterial substances produced by these strains were chemically different from the lateritiin group of antibiotics. Also, although these substances have not been obtained in a pure state, the marked differences in the chemical, as well as the biological, behaviour of the impure preparations indicate that more than one, and probably several, different antibacterial substances are produced by the various strains of group C. All the substances are heat-stable, but they differ from the lateritiin group in being insoluble in light petroleum, ether or chloroform.

Group D. Sixteen Fusarium strains were inactive against both Myco. phlei 1 and Staph. aureus in all tests made at frequent intervals up to 28 days of growth. Five of these (F. culmorum 2, F. sambucinum 3, $F .10$ and $F .88$ (from tomato) and $F .96$ (potato) were not tested further; the rest were tested against Myco. phlei 2 with repeat tests of Myco. phlei 1 for control. Five strains (F. dimerium, F. caeruleum, $F .95$ and $F .97$ from potato and $F .132$ from cob-nuts) were inactive against both Myco. phlei 1 and 2 but the remaining six, 
though again inactive against $M y c o$. phlei 1 , showed various degrees of activity against Myco. phlei 2 . Three strains, $F$. oxysporum cubense, $F .124$ and $F .127$ (hop canker) were inhibitory only in $1 / 5$ dilution and for a limited period; $F$. moniliforme-subglutinans 2 developed a maximum potency of $1 / 15$. F. aquaeductum and $F .94$ (potato) were inactive until the 12th day when a potency of 1/10 against $M y c o$. phlei 2 suddenly developed. The potency of $F .94$ filtrates remained constant until the 21st day; that of $F$. aquaeductum increased to a maximum of $1 / 20$ on the 20th day, dropping to $1 / 15$ on the 29th day. Since lateritiin and fructigenin are considerably more active against Myco. phlei 2 than against Myco. phlei 1 (see below), it may be that the antibiotics produced by these six strains of group D are of a similar type to those of group B, but are produced in amounts too small to be detected in tests of the culture fluids against $M y c o$. phlei 1 . This seems likely where maximum potencies of $1 / 5$ against $M y c o$. phlei 2 were obtained, but the case of $F$. aquaeductum, when a culture fluid of $1 / 20$ potency against $M y c o$. phlei 2 was inactive against Myco. phlei 1 , is more difficult to explain. No attempts were made to isolate the antibiotic substances from any of the group D cultures.

\section{Antibacterial activity of pure Fusarium antibiotics}

In group A two antibiotic substances, namely the pigments javanicin and oxyjavanicin produced by $F$. javanicum, have been isolated in a pure state (Arnstein, et al. 1946a,b).

In group $B$ antibacterial substances have been extracted from the culture fluids of eight strains. A preliminary account of five of these, namely lateritiin I and II, avenacein, sambucinin and fructigenin from strains of $\boldsymbol{F}$. lateritium, $F$. avenaceum, $\boldsymbol{F}$. sambucinum and $\boldsymbol{F}$. fructigenum respectively, has been published (Cook et al. 1947). These five substances are so similar in chemical behaviour as to leave no doubt that their biological activity is due to similar structural features, but both their chemical and antibacterial reactions show that they are distinct compounds. The differences in antibacterial behaviour are most marked against the two strains of Myco. phlei. Lateritiin I and II and fructigenin are much more effective against $M y c o$. phlei 2 than against Myco. phlei 1, avenacein is equally effective against both strains and sambucinin is considerably less active against Myco. phlei 2. Lateritiin I, lateritiin II and fructigenin are distinguished by the ratios of their activity against Staph. aureus, Strep. pyogenes and $B$. subtilis. The chemical identity of the three substances isolated from the unidentified Fusarium strains $F .135, F .136$ and $F .138$ was not fully established, but the similarity of the antibacterial activity of the crude culture fluids, the impure extracts and the pure crystalline antibiotic substances provides strong evidence of their identity with fructigenin. Enniatin, isolated from Fusarium orthoceras var. enniatinum by Gäumann, Roth, Ettlinger, Plattner \& Nager (1947) is very similar, both chemically and in antibacterial activity, to the antibiotics of group $B$.

Table 2 shows the highest dilutions of the nine Fusarium antibiotics which give complete bacteriostasis of five bacterial strains. Fusarium antibiotics are 
Table 2. Relative bacteriostatic action of nine Fusarium antibiotics against five bacterial strains, the potency against Mycobacterium phlei 1 being taken as 100

\begin{tabular}{|c|c|c|c|c|c|}
\hline Antibiotic & Myco. phlei 1 & $\begin{array}{l}\text { Myco. } \\
\text { phlei } 2\end{array}$ & $\begin{array}{l}\text { Staph. } \\
\text { aureus }\end{array}$ & $\begin{array}{c}\text { Strep. } \\
\text { pyogenes }\end{array}$ & B. subtilis \\
\hline Javanicin & $1 / 200,000(100)$ & 50 & 100 & 20 & 100 \\
\hline Lateritiin I & $1 / 200,000(100)$ & 160 & $\mathbf{2 5}$ & 20 & 40 \\
\hline Lateritiin II & $1 / 160,000(100)$ & 200 & 25 & 15 & 20 \\
\hline Avenacein & $1 / 160,000(100)$ & 100 & $12 \cdot 5$ & 6 & $\mathbf{3}$ \\
\hline Sambucinin & $1 / 200,000(100)$ & 25 & 20 & 10 & 5 \\
\hline Fructigenin & $1 / 200,000(100)$ & 150 & 15 & 25 & 10 \\
\hline 135 & $1 / 160,000(100)$ & 150 & 25 & 30 & 15 \\
\hline 137 & $1 / 150,000(100)$ & 183 & 26 & 33 & 13 \\
\hline 138 & $1 / 160,000(100)$ & 150 & 25 & $\mathbf{3 0}$ & 15 \\
\hline
\end{tabular}

bactericidal as well as bacteriostatic, although in most cases a considerably stronger concentration of the antibiotic is necessary for killing. Table 3 shows the result of an experiment to find the time required for bactericidal action in broth. One drop of a broth culture of Myco. phlei 1 was used as inoculum into each broth + antibiotic tube. Subcultures were made immediately and at intervals up to $48 \mathrm{hr}$. on nutrient agar plates and the colonies counted.

Table 3. Bactericidal action of four Fusarium antibiotics against Mycobacterium phlei 1 in broth

\begin{tabular}{cl} 
Antibiotic & \multicolumn{1}{c}{ Dilution } \\
Lateritiin I & $\mathbf{1 / 2 0 0 , 0 0 0}$ \\
Lateritiin I & $\mathbf{1} \mathbf{1 0 0 , 0 0 0}$ \\
Lateritiin II & $\mathbf{1 / 2 0 , 0 0 0}$ \\
Avenacein & $\mathbf{1 / 2 0 , 0 0 0}$ \\
Sambucinin & $\mathbf{1 / 2 0 , 0 0 0}$ \\
\hline & Control broth
\end{tabular}

Percentage of bacteria living after (hr.)

Growth of the few bacteria that survived for $24 \mathrm{hr}$. in the lateritiin I and II broths was much delayed, tiny colonies being only just visible after 3 days' incubation. Even the 1/200,000 dilution of lateritiin $I$, which is the highest dilution of this antibiotic to cause complete bacteriostasis of Myco. phlei 1 , is markedly bactericidal, though somewhat slower in action than the 1/100,000 dilution.

\section{Effect of blood serum on Fusarium antibiotics}

Lateritiin I and II, avenacein and sambucinin were tested in broth containing various amounts of horse serum, using Staph. aureus as the test organism. The results are given in Table 4. In the presence of serum a higher concentration of antibiotic is required for complete bacteriostasis but, except in the $\mathbf{4 0} \%$ serum test of lateritiin I, normal growth of Staph. aureus occurred only in the same dilution of antibiotic in presence or absence of serum. In the dilutions causing partial inhibition there was a marked decrease in the growth of Staph. aureus and the bacteria were strongly agglutinated. Staph. 
Table 4. The effect of blood serum on the activity of Fusarium antibiotics against Staphylococcus aureus

\begin{tabular}{|c|c|c|c|c|}
\hline \multirow[b]{2}{*}{ Antibiotic } & \multirow[b]{2}{*}{$\begin{array}{c}\text { Serum } \\
(\%)\end{array}$} & \multicolumn{3}{|c|}{ Dilution of antibiotic giving } \\
\hline & & $\begin{array}{l}\text { Complete } \\
\text { inhibition }\end{array}$ & $\begin{array}{c}\text { Partial } \\
\text { inhibition }\end{array}$ & $\begin{array}{l}\text { Normal } \\
\text { growth }\end{array}$ \\
\hline Lateritiin I & $\begin{array}{l}- \\
10 \\
20 \\
25 \\
40\end{array}$ & $\begin{array}{l}1 / 40,000 \\
1 / 20,000 \\
1 / 10,000 \\
1 / 10,000 \\
1 / 10,000\end{array}$ & $\begin{array}{l}1 / 50,000 \\
1 / 40,000 \\
1 / 40,000 \\
1 / 20,000 \\
1 / 20,000\end{array}$ & $\begin{array}{l}1 / 80,000 \\
1 / 80,000 \\
1 / 80,000 \\
1 / 80,000 \\
1 / 40,000\end{array}$ \\
\hline Lateritiin II & $\begin{array}{l}\overline{10} \\
25\end{array}$ & $\begin{array}{l}1 / 40,000 \\
1 / 20,000 \\
1 / 20,000\end{array}$ & $\begin{array}{l}\text { (No higher } \\
\text { 1/40,000 }\end{array}$ & $\begin{array}{c}1 / 80,000 \\
\text { on tested) } \\
1 / 80,000\end{array}$ \\
\hline Avenacein & $\begin{array}{l}- \\
10 \\
25\end{array}$ & $\begin{array}{c}1 / 10,000 \\
1 / 5,000\end{array}$ & $\begin{array}{l}1 / 20,000 \\
1 / 10,000 \\
1 / 20,000\end{array}$ & $\begin{array}{c}1 / 40,000 \\
\frac{-}{1 / 40,000}\end{array}$ \\
\hline Sambucinin & $\begin{array}{l}- \\
10 \\
25\end{array}$ & $\begin{array}{l}1 / 40,000 \\
1 / 20,000 \\
1 / 10,000\end{array}$ & $\begin{array}{c}-\overline{1 / 40,000} \\
1 / 20,000 \\
\text { to } 1 / 40,0\end{array}$ & $\frac{1 / 80,000}{1 / 80,000}$ \\
\hline
\end{tabular}

aureus grew normally in control tubes of broth containing 25 or $40 \%$ serum, and there was considerably heavier growth in these tubes than in the control tubes without serum. Therefore in comparing the activity of the antibiotics in the presence and absence of serum allowance should be made for the fact that the serum broth was a decidedly more favourable medium for the growth of Staph. aureus than the plain nutrient broth.

\section{Destruction of lateritiin in cultures}

Cook et al. (1947) suggested that the Fusarium antibiotic substances are normal but usually transient products of metabolism which accumulate in the culture fluids in detectable quantities only under abnormal cultural conditions. If this be so, the absence of activity in the culture fluids of some Fusarium strains might be due, not to failure to produce antibiotic substances, but to their rapid conversion into other compounds by the continued growth of the culture. This view is supported by the fact that the inactive strains were nearly always the most vigorous in growth. The following experiments were designed to test this suggestion.

Experiment 1. A solution of pure lateritiin in Czapek-Dox medium, having a potency of 1/10 against Myco. phlei 1 , was divided into four equal parts, one of which was left uninoculated for control. The other three parts were inoculated respectively with: $F .97$, a very vigorously growing strain but producing no antibiotic; $\boldsymbol{F}$. lateritium 1 , the strain from which lateritiin was produced; a degenerate culture of $\boldsymbol{F}$. lateritium which gave a very poor gelatinous growth. The cultures were incubated at $25^{\circ}$ and tested against $M y c o$. phlei 1 after 5 , 7 and 10 days. The culture of $F .97$ was active at $1 / 5$ but not at $1 / 10$ on the 5th day and was inactive on the 10th day when the two $F$. lateritium cultures 
and the control were still active in $1 / 10$ dilution. Thus the lateritiin was destroyed only by the vigorously growing strain $F .97$.

Experiment 2. F. lateritium was grown on the standard Eupeptone medium until the culture fluid had developed a potency of 1/10 against Myco. phlei 1 . The fluid was then filtered to remove the mycelium, heated to $100^{\circ}$ for $10 \mathrm{~min}$. to sterilize, and dispensed into three sterile flasks. The first flask was kept as control, the second was inoculated with the parent culture of $\boldsymbol{F}$. lateritium and the third with the vigorous grower $F$. 97. The flasks were incubated at $25^{\circ}$. The difference in growth of the two Fusarium strains was very marked. Growth was visible in the $F .97$ flask after $24 \mathrm{hr}$. and the mycelium had spread throughout the medium in $48 \mathrm{hr}$. F. lateritium, however, showed no sign of growth in $24 \mathrm{hr}$. and there was only a very slight development of mycelium round the piece of inoculum on the 3rd day. Thus an old culture filtrate of $F$. lateritium is a good medium for the growth of the $F .97$ strain which does not produce antibiotic, but a very poor medium for $F$. lateritium. Tests at 4 and 7 days showed destruction of lateritiin by $F$. 97 but not by $F$. lateritium. The cultures were left incubating until the 25th day, when they were retested; the control uninoculated fluid had its original potency 1/10 dilution against Myco. phlei 1, the $\boldsymbol{F}$. lateritium fluid was still effective in $1 / 5$ dilution, but all traces of activity had disappeared from the $F .97$ culture.

Experiment 3. Strain $F .97$ was seeded into tubes containing pure lateritiin in (a) distilled water, and (b) a weak (1/5 usual) Czapek-Dox medium; both solutions were initially active in 1/20 dilution against Myco. phlei 1. After 3 days' incubation at $25^{\circ}(a)$ was only partially active against $M y c o$. phlei 1 in $1 / 5$ dilution. The destruction of lateritiin in solution $(b)$ took longer, probably because there was an alternative supply of nutrient material available, but both solutions were quite inactive on the 10th day. The control tubes of each solution were unaltered in potency.

Experiment 4. F. lateritium and the non-producing strain $F .97$ were grown together in mixed culture and, as control, an equal quantity of culture medium was inoculated with pure $F$. lateritium. Both strains grew well in the mixed culture, which consisted of the pure white felt of $F$. lateritium and the deep red felt of $\boldsymbol{F} .97$. The pure culture of $\boldsymbol{F}$. lateritium developed normally, i.e. had a potency of $1 / 10$ on the 4th day, rising to $1 / 20$ on the 11th with a fall to $1 / 10$ again on the 21 st and 28rd days. The mixed culture was active in $1 / 5$ only on the 4th day and did not at any time reach a potency of more than $1 / 10$, which fell again to $1 / 5$ on the 23rd day. These experiments, which indicate that a vigorously growing Fusarium strain which does not produce antibiotic is capable of inactivating lateritiin, support the theory that Fusarium antibiotic substances are normal products of the fungal metabolism.

\section{Antifungal action of Fusarium species}

The Fusarium strains tested had little or no antifungal action: sometimes there was slight mutual antagonism between species grown on the same cultureplate but generally no inhibitory action was observed. Arnstein et al. (1946b) 
noted that javanicin is almost without antifungal activity. Lateritiin, except for causing a slight initial lag in growth of Botrytis cinerea and Verticillium sp., also showed no antifungal activity.

The author wishes to thank all those to whom she is indebted for Fusarium cultures, in particular Mr M. H. Moore (who sent the $F$. lateritium culture from which lateritiin was obtained) and Miss Joan Moore. The chemical work was carried out in the organic chemistry department of the Imperial College by Drs H. R. V. Arnstein, S. F. Cox and T. H. Farmer under the direction of Dr A. H. Cook. Thanks are due to the Medical Research Council for financial assistance.

\section{REFERENCES}

Arnstein, H. R. V., Cook, A. H. \& Lacey, M. S. (1946a). An antibiotic pigment from Fusarium javanicum. Nature, Lond., 157, 333.

Arnstern, H. R. V., Cook, A. H. \& Laceex, M. S. (1946b). Production of antibiotics by fungi. Part II. Production by Fusarium javanicum and other Fusaria. Brit. J. exp. Path. 27, 849.

Cook, A. H., Cox, S. F., Farmer, T. H. \& Lacey, M. S. (1947). Production of antibiotics by Fusaria. Nature, Lond., 160, 31.

Gäumann, E., Roth, S., Ettuinger, L., Plattiner, P. A. \& Nager, U. (1947). Enniatin, ein neues gegen Mycobakterien wirksames Antibioticum. Experientia, 3, 202.

(Received 14 May 1949) 